Article

\title{
On Sluggish Diffusion in Fcc Al-Co-Cr-Fe-Ni High-Entropy Alloys: An Experimental and Numerical Study
}

\author{
Qin Li ${ }^{1}$, Weimin Chen ${ }^{1}$, Jing Zhong ${ }^{1}$, Lijun Zhang ${ }^{1, *}$, Qing Chen ${ }^{2}$ and Zi-Kui Liu ${ }^{3}$ \\ 1 State Key Laboratory of Powder Metallurgy, Central South University, Changsha 410083, China; \\ qinli333@csu.edu.cn (Q.L.); chenweiming126@jnu.edu.cn (W.C.); zhongjingjogy@csu.edu.cn (J.Z.) \\ 2 Thermo-Calc Software AB, Råsundavägen 18, SE-16967 Solna, Sweden; qing@thermocalc.se \\ 3 Department of Materials Science and Engineering, Pennsylvania State University, University Park, \\ PA 16802, USA; prof.zikui.liu@psu.edu \\ * Correspondence: xueyun168@gmail.com or lijun.zhang@csu.edu.cn; \\ Tel.: +86-731-8887-7963; Fax: +86-731-8871-0855
}

Received: 5 December 2017; Accepted: 25 December 2017; Published: 30 December 2017

\begin{abstract}
High-throughput measurement using the numerical inverse method combined with the diffusion multiple technique was employed to determine the composition-dependent interdiffusion coefficients in fcc Al-Co-Cr-Fe-Ni high-entropy alloys at 1273, 1323, and $1373 \mathrm{~K}$. The reliability of the obtained interdiffusion coefficients was confirmed by comparing the model-predicted composition/interdiffusion flux profiles with the experimental data. The tracer diffusivities of the components were then predicted based on the obtained interdiffusion coefficients and the simplified thermodynamic description. The diagonal interdiffusion coefficients in the present high-entropy alloys were comprehensively compared with those in conventional fcc alloys. Therefore, the sluggish diffusion effect does not apply for all the elements in the present fcc $\mathrm{Al}-\mathrm{Co}-\mathrm{Cr}-\mathrm{Fe}-\mathrm{Ni}$ high-entropy alloys. A similar result was also observed for the evaluated tracer diffusivities.
\end{abstract}

Keywords: Al-Co-Cr-Fe-Ni; high-entropy alloys; diffusion; numerical inverse method; diffusion multiple

\section{Introduction}

The high-entropy alloys (HEAs) (or multi-principle element alloys (MPEAs)) initially proposed by Yeh and Huang in 1995 [1] have drawn increasing attention because of their comprehensive beneficial mechanical, magnetic, and electrochemical characteristics. These characteristics render these HEAs suitable for numerous potential uses. These applications include structural materials for transportation, heat- or wear-resistant coatings, and other uses in energy and nuclear industries [2,3]. Distinct from conventional alloys, HEAs were originally defined as alloys consisting of more than four principal metallic elements, and exhibiting high mixing entropy when they are in a high-temperature solid solution or liquid state [4].

The aforementioned outstanding properties are usually directly attributed to the four core effects on HEAs [2,5]. Among these effects, sluggish diffusion is identified as the one responsible for many distinct characteristics of HEAs [6], such as the deceleration of grain growth, exceptional thermal stability, and formation of nanostructures. Most recent findings [7] suggest that, within the past ten years, the number of studies on diffusion in HEAs has grown from three papers to 30 papers each year. Moreover, a significant number of studies on the measurement of diffusivities in HEAs have also been conducted [8-13], aimed at verifying the occurrence of sluggish diffusion in HEAs. Table 1 summarizes all available experimental measurements of diffusivities in different HEAs in the 
literature. Tsai et al. [8] reported on the tracer diffusivities of five elements in the Co-Cr-Fe-Mn-Ni quinary system. As presented in Table 1, sluggish diffusion was observed when the comparison was made against the inverse of the homologous temperature $T_{\mathrm{m}} / T$. Beke and Erdélyi [9] confirmed the occurrence of sluggish diffusion in HEAs by re-analyzing the data presented in Ref. [8]. Kulkarni and Chauhan [10] investigated the average interdiffusivities in the Co-Cr-Fe-Ni quaternary system and showed that the diffusion was sluggish in this quaternary system. Dabrowa et al. [11] measured the tracer diffusivities of the elements, except that for $\mathrm{Al}$, in the $\mathrm{Al}-\mathrm{Co}-\mathrm{Cr}-\mathrm{Fe}-\mathrm{Ni}$ quinary system and found the occurrence of the sluggish diffusion effect in HEAs.

Table 1. Summary of experimental information on diffusivities in different high-entropy alloys (HEAs) available in the literature and in the present work.

\begin{tabular}{|c|c|c|c|c|c|}
\hline HEA Systems & Method & Type of Diffusivity & $\begin{array}{c}\text { Sluggish } \\
\text { Diffusion } \\
\text { (Yes/No) }\end{array}$ & Note & References \\
\hline $\mathrm{Co}-\mathrm{Cr}-\mathrm{Fe}-\mathrm{Ni}$ & Dayananda-Sohn analysis & Average interdiffusivity & Yes & $T$ & Kulkarni and Chauhan [10] \\
\hline \multirow{5}{*}{$\mathrm{Co}-\mathrm{Cr}-\mathrm{Fe}-\mathrm{Mn}-\mathrm{Ni}$} & Quasi-binary approach & Tracer diffusivity & Yes & $T_{\mathrm{m}} / T$ & Tsai et al. [8] \\
\hline & Semi-empirical rules & Tracer diffusivity & Yes & $T_{\mathrm{m}} / T$ & Beke and Erdélyi [9] \\
\hline & Radiotracer technique & Tracer diffusivity & $\begin{array}{l}\text { Yes } \\
\text { No }\end{array}$ & $\begin{array}{c}T_{\mathrm{m}} / T \\
1 / T\end{array}$ & Vaidya et al. [12] \\
\hline & Numerical inverse method & $\begin{array}{l}\text { Interdiffusivity } \\
\text { Tracer diffusivity }\end{array}$ & $\begin{array}{l}\text { Yes } \\
\text { No }\end{array}$ & $1 / T$ & Chen and Zhang [13] \\
\hline & Manning's approach & Interdiffusivity & / & / & Verma et al. [14] \\
\hline \multirow{3}{*}{$\mathrm{Al}-\mathrm{Co}-\mathrm{Cr}-\mathrm{Fe}-\mathrm{Ni}$} & Levenberg-Marquardt method & Tracer diffusivity & Yes & $1 / T$ & Dabrowa et al. [11] \\
\hline & \multirow[b]{2}{*}{ Numerical inverse method } & Interdiffusivity & Partial $(\mathrm{Al}, \mathrm{Cr}, \mathrm{Fe})$ & $1 / T$ & \multirow[b]{2}{*}{ This work } \\
\hline & & Tracer diffusivity & Partial $(\mathrm{Cr}, \mathrm{Fe})$ & $\begin{array}{c}1 / T \\
T_{\mathrm{m}} / T\end{array}$ & \\
\hline
\end{tabular}

Vaidya et al. [12] recently measured the tracer diffusivities of $\mathrm{Ni}$ in the equiatomic $\mathrm{Co}-\mathrm{Cr}-\mathrm{Fe}-\mathrm{Ni}$ and $\mathrm{Co}-\mathrm{Cr}-\mathrm{Fe}-\mathrm{Mn}-\mathrm{Ni}$ alloys and argued that at any given absolute temperature, the diffusion rate of $\mathrm{Ni}$ in the $\mathrm{Co}-\mathrm{Cr}-\mathrm{Fe}-\mathrm{Mn}-\mathrm{Ni}$ alloy was even faster than that in the $\mathrm{Co}-\mathrm{Cr}-\mathrm{Fe}-\mathrm{Ni}$ alloy. This difference indicated that the so-called sluggish diffusion in HEAs was not inevitable. Chen and Zhang [13] recently measured the composition-dependent interdiffusion coefficients in the $\mathrm{Co}-\mathrm{Cr}-\mathrm{Fe}-\mathrm{Mn}-\mathrm{Ni}$ quinary system. Comparison of the results revealed that, for $\mathrm{Co}-\mathrm{Cr}-\mathrm{Fe}-\mathrm{Mn}-\mathrm{Ni} \mathrm{HEAs}$, the sluggish diffusion feature was plausible for the interdiffusion coefficients rather than the tracer diffusivities. In addition, Verma et al. [14] reported on interdiffusivities in the Co-Cr-Fe-Mn-Ni quinary system; however, their purpose was to emphasize the importance of diffusional interactions in controlling interdiffusion in the Co-Cr-Fe-Mn-Ni HEA rather than examine the sluggish diffusion in HEAs. Several investigations on diffusivities in HEAs have been reported, but whether the diffusion in HEAs is sluggish remains unclear. Thus, more experimentally measured diffusivities, including the $\mathrm{Al}-\mathrm{Co}-\mathrm{Cr}-\mathrm{Fe}-\mathrm{Ni}$ quinary system which seems to be ignored, compared with the $\mathrm{Co}-\mathrm{Cr}-\mathrm{Fe}-\mathrm{Mn}-\mathrm{Ni}$ system, need to be provided.

The concentration-dependent interdiffusion coefficients in alloy systems, mainly ternary systems, could be determined by combining the single-phase diffusion couple/multiple technique and the previously developed numerical inverse method by the present research group [15-17]. With the numerical inverse method, the interdiffusion coefficients along the entire diffusion paths of the diffusion couple(s)/multiple can be efficiently obtained based on the experimentally measured composition-distance profiles. The advanced feature of this type of numerical inverse method is attributable to its applicability in different multi-component solid solution alloys, such as binary alloys, ternary alloys, and HEAs. Moreover, the presence or absence of the thermodynamic description for the target alloy exerts no influence on the quality of the evaluated interdiffusion coefficients [16]. This numerical inverse approach has thus been successfully used to evaluate concentration-dependent interdiffusion coefficients in different alloys, including fcc $\mathrm{Cu}-\mathrm{Ag}-\mathrm{Sn}$ alloys [18], fcc Ni-Al-Ta [19], and Ni-Al-Mo [20] alloys, bcc Fe-Mn-Si alloys [21], and fcc Co-Cr-Fe-Mn-Ni HEAs [13]. Their reliability was also verified by direct comparison with the 
determined results by using the traditional Matano-Kirkaldy method and the reported data in the literature.

Thus, in the present study, high-throughput measurement of the composition-dependent interdiffusion coefficients in fcc $\mathrm{Al}-\mathrm{Co}-\mathrm{Cr}-\mathrm{Fe}-\mathrm{Ni}$ alloys at different temperatures is to be conducted by combining the recently developed numerical inverse method with the efficient single-phase diffusion multiple technique. The model-predicted composition profiles and interdiffusion fluxes with the experimental data are to be comprehensively compared to verify the reliability of the obtained interdiffusion coefficients. Moreover, the corresponding tracer diffusion coefficients of each component are estimated and compared with the literature data in fcc pure elements and lower-order alloys from which the sluggish diffusion effect is analyzed.

\section{Experimental Procedure}

Starting materials include pure aluminum (purity: 99.99 wt \%), cobalt (purity: $99.98 \mathrm{wt} \%$ ), chromium (purity: $99.95 \mathrm{wt} \%$ ), iron (purity: $99.98 \mathrm{wt} \%$ ), and nickel (purity: $99.995 \mathrm{wt} \%$ ). Three different Al-Co-Cr-Fe-Ni alloys-i.e., $\mathrm{Co}_{25.33} \mathrm{Cr}_{25.77} \mathrm{Fe}_{24.53} \mathrm{Ni}_{24.37}$ (in at \%, denoted as Alloy 1), $\mathrm{Al}_{4.88} \mathrm{Co}_{29.53} \mathrm{Cr}_{18.58} \mathrm{Fe}_{19.62} \mathrm{Ni}_{27.39}$ (in at \%, denoted as Alloy 2), and $\mathrm{Al}_{6.64} \mathrm{Co}_{23.82} \mathrm{Cr}_{23.66} \mathrm{Fe}_{23.01} \mathrm{Ni}_{22.87}$ (in at \%, denoted as Alloy 3) - which were scrupulously chosen according to recent thermodynamic predictions [22], were arc-melted under an argon atmosphere by a non-consumable tungsten electrode. All samples were re-melted more than four times to enhance their homogeneities. The ingots were subsequently cut into blocks approximately measuring $4 \mathrm{~mm} \times 4 \mathrm{~mm} \times 8 \mathrm{~mm}$ and homogenized at $1373 \mathrm{~K} \pm 3 \mathrm{~K}$ for $168 \mathrm{~h}$ after being placed in evacuated and sealed quartz tubes, followed by quenching in water. All annealed alloys were subjected to X-ray diffraction measurements (Bruker D8 Advance, Bruker, Germany) and confirmed to be located within the fcc single-phase region, as shown in Figure 1. Three diffusion multiples were subsequently prepared by stacking the polished and cleaned blocks up in the sequence, as schematically shown in Figures 2-4, in a vacuum hot-pressing furnace under a load of $5 \mathrm{MPa}$ for $2 \mathrm{~h}$ at $1273 \mathrm{~K}, 1323 \mathrm{~K}$, and $1373 \mathrm{~K}$. The three diffusion multiples were ground to remove surface contamination and then annealed for another $46 \mathrm{~h}$ at $1273 \mathrm{~K}, 1323 \mathrm{~K}$, and $1373 \mathrm{~K}$, followed by quenching in water. Finally, the concentration profiles of the diffusion multiples were measured using electron probe microanalysis (EPMA, JXA-8230, JEOL, Tokyo, Japan) on the polished section made by standard metallographic preparation. For each component, the variations in alloy compositions were limited to $0.5 \%$.

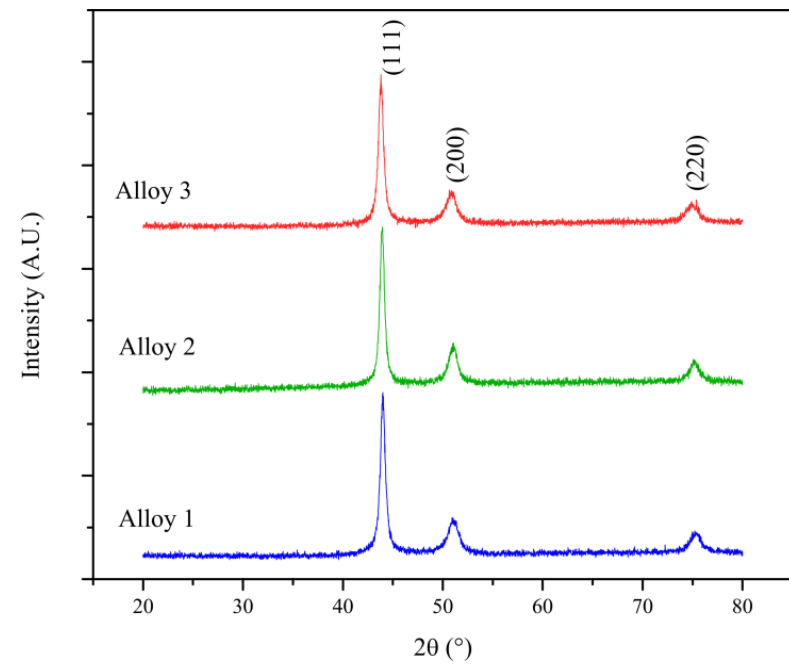

Figure 1. X-ray diffraction patterns of Alloy $1 \quad\left(\mathrm{Co}_{25.33} \mathrm{Cr}_{25.77} \mathrm{Fe}_{24.53} \mathrm{Ni}_{24.37}\right)$, Alloy 2 $\left(\mathrm{Al}_{4.88} \mathrm{Co}_{29.53} \mathrm{Cr}_{18.58} \mathrm{Fe}_{19.62} \mathrm{Ni}_{27.39}\right)$ and Alloy $3\left(\mathrm{Al}_{6.64} \mathrm{Co}_{23.82} \mathrm{Cr}_{23.66} \mathrm{Fe}_{23.01} \mathrm{Ni}_{22.87}\right)$, indicating that all of them locate in the single fcc phase region. 


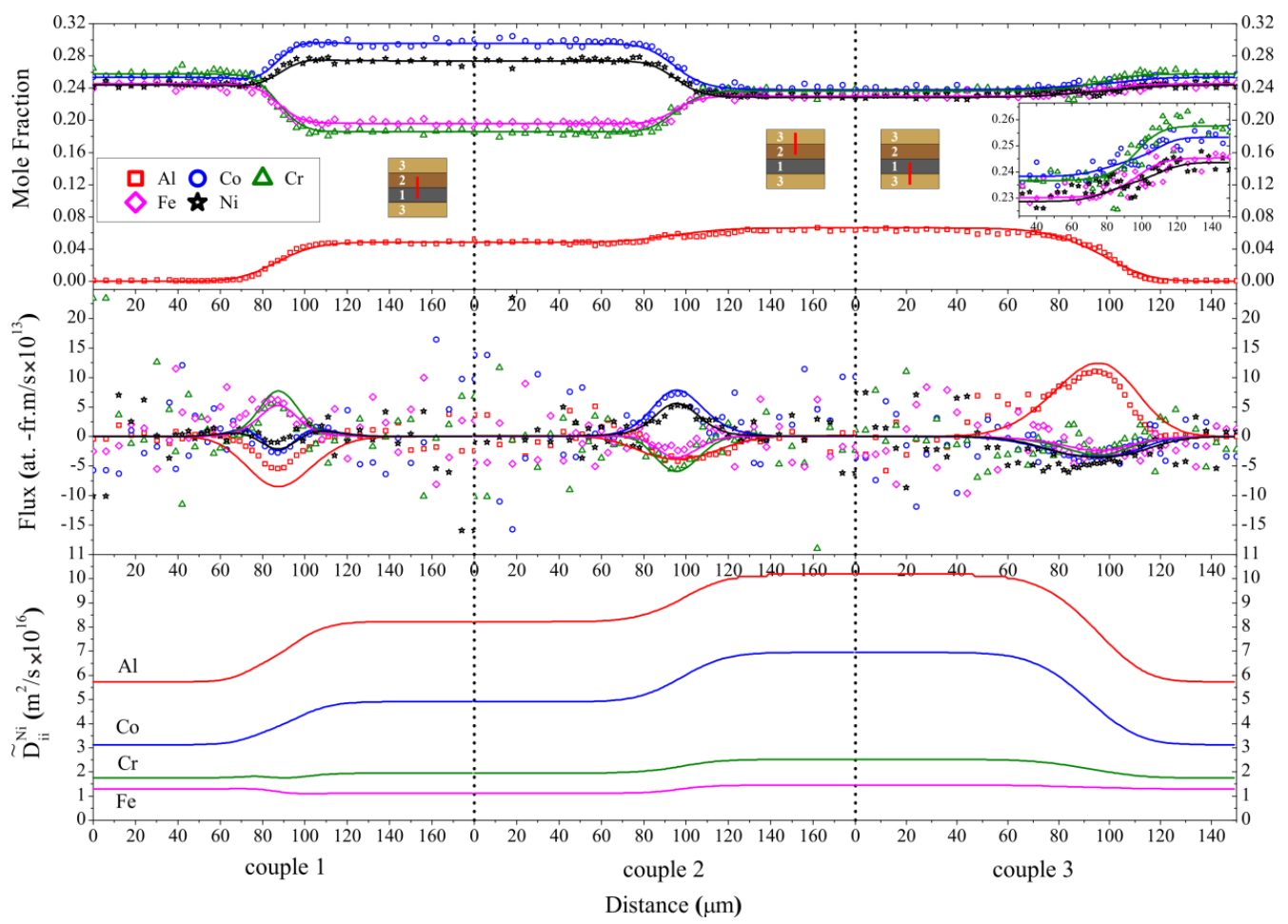

Figure 2. Comparison between the experimental and simulated concentration profiles/interdiffusion fluxes of diffusion couples annealed at $1273 \mathrm{~K}$ for $46 \mathrm{~h}$ as well as the evaluated diagonal interdiffusivities. Symbols are due to the experimental measurements.

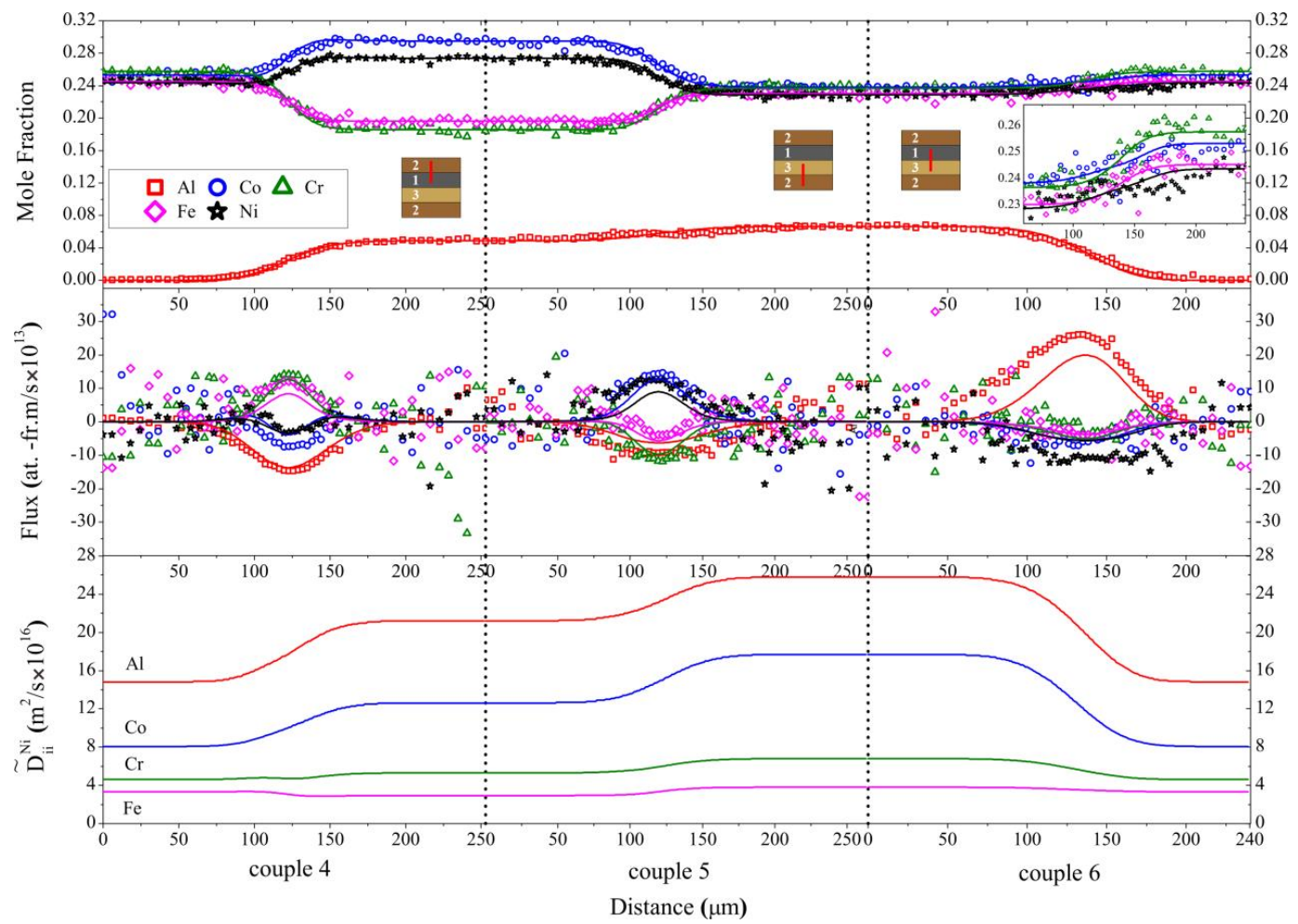

Figure 3. Comparison between the experimental and the simulated concentration profiles/interdiffusion fluxes of diffusion couples annealed at $1323 \mathrm{~K}$ for $46 \mathrm{~h}$ as well as the evaluated diagonal interdiffusivities. Symbols are due to the experimental measurements. 


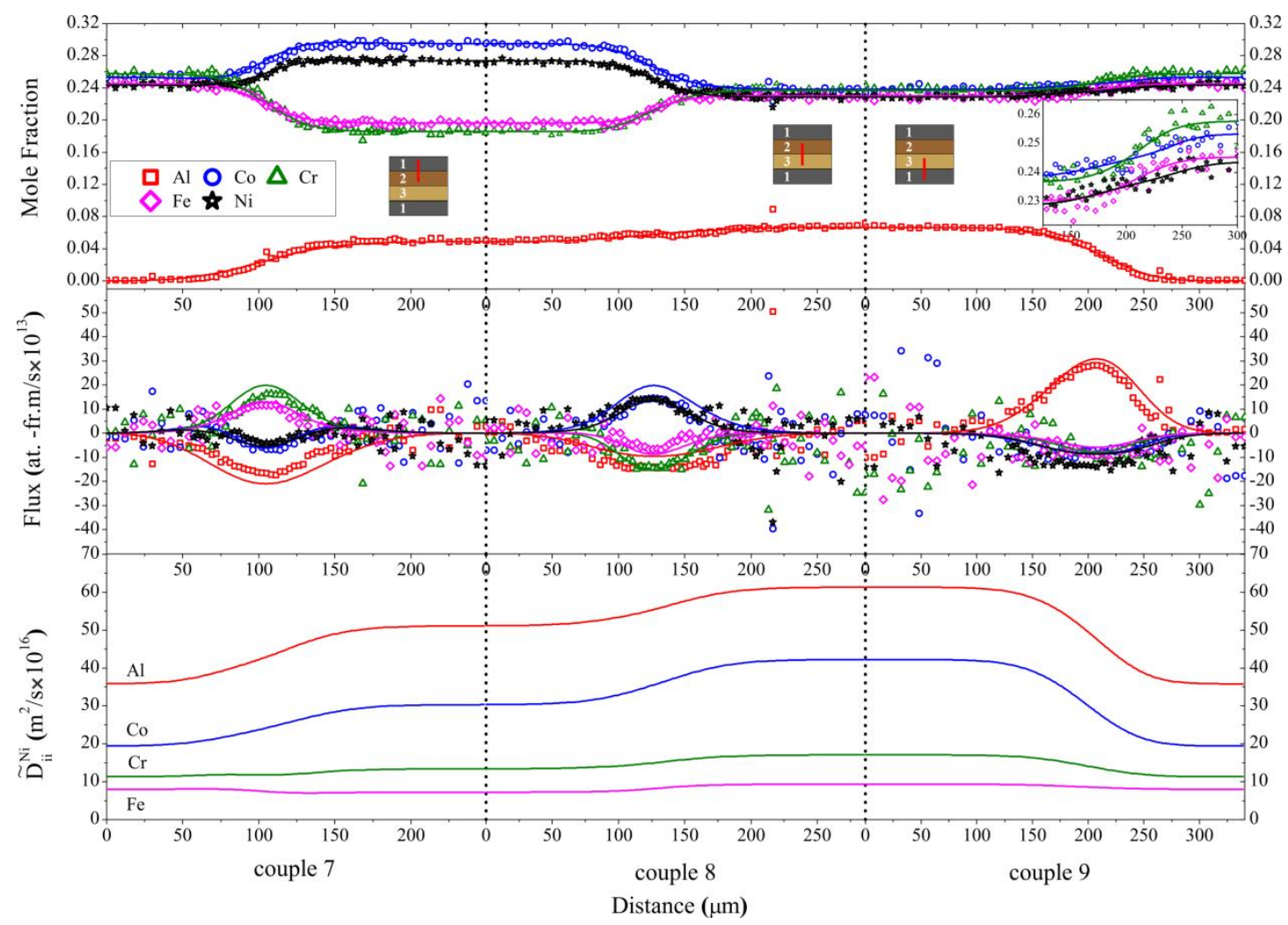

Figure 4. Comparison between the experimental and the simulated concentration profiles/interdiffusion fluxes of diffusion couples annealed at $1373 \mathrm{~K}$ for $46 \mathrm{~h}$ as well as the evaluated diagonal interdiffusivities. Symbols are due to the experimental measurements.

\section{Numerical Inverse Method}

The determined concentration profiles at different temperatures were used to retrieve the composition- and temperature-dependent interdiffusivity matrices in fcc $\mathrm{Al}-\mathrm{Co}-\mathrm{Cr}-\mathrm{Fe}-\mathrm{Ni}$ alloys by using the recent numerical inverse method [15-17]. In an $N$-component phase, the composition of component $i$ changes according to Fick's second law:

$$
\frac{\partial c_{i}}{\partial t}=\frac{\partial}{\partial x}\left(\sum_{j}^{N-1} \widetilde{D}_{i j}^{N} \frac{\partial c_{j}}{\partial x}\right) \quad(i=1,2, \ldots, N-1)
$$

where $t$ is the diffusion time, $x$ is the diffusion distance, $c_{i}$ is the composition of component $i$, and $\widetilde{D}_{i j}^{N}$ is either the diagonal or off-diagonal interdiffusion coefficient (component $N$ is chosen as the solvent). The interdiffusivity $\widetilde{D}_{i j}^{N}(i, j=A, B, \ldots, N-1)$ can be in relation to mobility $M_{i}$ by Manning's random alloy model expressed as

$$
\begin{aligned}
\widetilde{D}_{i j}^{N} & =R T\left(M_{i} \Phi_{i j}^{N}-c_{i} \sum_{m} M_{m} \Phi_{m j}^{N}\right) \\
& +s\left[M_{i}-\sum_{m}\left(c_{m} M_{m}\right)\right]\left[\frac{2 c_{i} R T \sum_{m}\left(M_{m} \Phi_{m j}^{N}\right)}{A_{0} \sum_{m}\left(c_{m} M_{m}\right)}\right]
\end{aligned}
$$

where $T$ is the temperature, and $R$ is the gas constant. On the right-hand side of Equation (2), the second term indicates the vacancy-wind effect. The contribution of this effect can be monitored by the parameter $s$ equaling either 0 or 1 . In the present study, $s$ is equal to 0 ; that is, the vacancy-wind 
effect is disregarded. $A_{0}$ is one parameter only depending on the crystal structure, and for fcc crystals, it equals to 7.15. $\Phi_{i j}^{N}$ is the thermodynamic factor being expressed by

$$
\Phi_{i j}^{N}=\frac{c_{i}}{R T}\left(\frac{\partial \mu_{i}}{\partial c_{j}}-\frac{\partial \mu_{i}}{\partial c_{N}}\right)
$$

where $\mu_{i}$ is the chemical potential. The value of $\mu_{i}$ can be derived based on the corresponding thermodynamic descriptions. In the numerical inverse method [15-17], the degree of fit of the model-predicted composition/interdiffusion flux profiles to the experimental ones determines the quality of the obtained interdiffusion coefficients. To evaluate the atomic mobility, the thermodynamic factor is needed. For the numerical inverse method, the mobility parameters and the thermodynamic factors can be treated only as the numerical parameters with no physical meaning under the condition that the thermodynamic description is absent for the target alloy [15-17]. In the CALPHAD (Computer Coupling of Phase Diagrams and Thermochemistry) formalism, the mobility $M_{i}$ in a phase composed of $N$ components can be expanded as

$$
\begin{aligned}
M_{i}= & \frac{1}{R T} \exp \\
& \left(\frac{\sum_{j=A}^{N} c_{j} \Delta G_{i}^{j}+\sum_{j} \sum_{k \neq j} c_{j} c_{k} \Delta G_{i}^{j, k}+\sum_{j} \sum_{k \neq j} \sum_{l \neq j, k} c_{j} c_{k} c_{l} \Delta G_{i}^{j, k, l}+\ldots}{R T}\right)
\end{aligned}
$$

where $\Delta G_{i}^{j}$ is the end-member for the diffusion of component $i$ in component $j$, and $\Delta G_{i}^{j, k}$ and $\Delta G_{i}^{j, k, l}$ are the interaction parameters in the binary and ternary systems, respectively. Thus, the concentration profiles of component $i$ can be readily simulated by combining Equations (1)-(4).

In accordance with the study by Chen et al. [16], the more sensitive interdiffusion flux is also considered. According to Fick's first law, the interdiffusion flux of component $i$ in an $N$-component phase is

$$
\widetilde{J}_{i}^{c a l}=-\sum_{j}^{N-1} \widetilde{D}_{i j}^{N} \frac{\partial c_{j}}{\partial x} \quad(i=1,2, \ldots, N-1)
$$

whereas the experimental interdiffusion flux of component $i$ can be obtained on the basis of the experimental concentration profiles, as follows:

$$
\widetilde{J}_{i}^{\exp }=\frac{c_{i}^{L}-c_{i}^{R}}{2 t}\left[\begin{array}{l}
Y_{i}^{\prime} \int_{-\infty}^{x^{\prime}}\left(1-Y_{i}\right) d x+\left(1-Y_{i}^{\prime}\right) \\
\int_{x^{\prime}}^{\infty} Y_{i} d x
\end{array}\right]
$$

where $Y_{i}\left(Y_{i}=\left(c_{i}-c^{L}\right) /\left(c^{R}-c^{L}\right)\right)$ is a normalized composition variable, and $c^{R}$ and $c^{L}$ are the compositions of component $i$ on the far right and far left of the diffusion couple, respectively.

During the evaluation of interdiffusion coefficients, the computed interdiffusion coefficients are used to simulate the composition profiles of the components according to Fick's second law. An optimal set of model parameters in Equation (4), such as $\Delta G_{i}^{j}, \Delta G_{i}^{j, k}$, and $\Delta G_{i}^{j, k, l}$, is evaluated by iterative fitting until the error between the calculated and the experimentally measured concentration and interdiffusion flux profiles is minimized:

$$
\min \langle\text { error }\rangle=\min \left\langle w_{c} \sum_{i=A}^{N} \sum_{j=1}^{N u m} \frac{\left(\left|c_{i j}^{c a l}-c_{i j}^{\exp }\right|\right)}{c_{i j}^{\exp }}+w_{J} \sum_{i=A}^{N} \sum_{j=1}^{N u m} \frac{\left(\left|\widetilde{J}_{i j}^{c a l}-\widetilde{J}_{i j}^{\exp }\right|\right)}{\left|\widetilde{J}_{i j}^{\exp }\right|}\right\rangle
$$

where $c_{i j}^{c a l}$ and $\widetilde{J}_{i j}^{c a l}$ are the calculated concentration and interdiffusion flux of component $i$ at the $j$ th point, and $c_{i j}^{\exp }$ and $\widetilde{J}_{i j}^{\text {exp }}$ are the analogously experimental ones. Num denotes the number of experimental data. $w_{c}$ and $w_{J}$ represent the weights of concentration and interdiffusion flux during the minimization. In general, they both are set to 0.5 . Thus, the composition-dependent interdiffusivities 
in the target can be evaluated using Equations (1)-(7), and the composition-dependent interdiffusion coefficients in the target can be computed using Equation (2) on the basis of the optimal set of model parameters.

\section{Results and Discussion}

The composition profiles of the components in the three diffusion multiples measured by EPMA are presented in Figures 2-4. The corresponding interdiffusion fluxes evaluated using Equation (6) are also shown in the plots. All experimental data are denoted by symbols in Figures $2-4$. As can be seen from the figures, the simulated composition profiles are in good agreement with the experimental results. For the interdiffusion flux profiles, however, there exist relatively large deviations between the experimental results and the corresponding simulated ones. In the present work, all the interdiffusion flux points were directly evaluated from the raw experimental concentration points. No extra smooth and fitting treatments were used in order to stick to the original experimental information, because the interdiffusion flux is related to the gradient of composition, and thus is greatly sensitive to the uncertainty of the composition profiles over the diffusion region, which cause relatively large uncertainty for the present quinary high-entropy alloys. Besides, for the numerical inverse method, the experimental composition profiles are used as the primary observation for the first step, and then the additional "experimental" interdiffusion flux information that are sensitive to the optimization parameters can be considered for speeding up the numerical convergence [15-17]. Moreover, the position and value of the peak for the interdiffusion flux are much more important than the values outside the diffusion region, which should be 0 theoretically. Thus, the relatively large scattering values for the interdiffusion flux outside the diffusion region will not influence the quality of the evaluated interdiffusivities. By using the numerical inverse method [15-17], the concentration-dependent interdiffusion coefficients along the diffusion paths in the three diffusion multiples were effectively determined based on the experimentally measured concentration profiles. The average relative uncertainty for all the interdiffusion coefficients was evaluated to around $30 \%$ by using the error propagation method [18-21]. In the current study, Ni is regarded as the dependent component for interdiffusivity notation. In fact, the dependent component can be chosen arbitrarily, and different notations of interdiffusivities with different dependent components can be equivalently converted into each other [13]. The fcc phase in the quinary Al-Co-Cr-Fe-Ni system was simply considered as an ideal solution during the evaluation of the interdiffusion coefficients. In this case, the thermodynamic factor $\Phi_{i j}^{N}(i, j \neq N)$ is equal to 0 if $i$ is not $j$ and is equal to 1 when $i$ is $j$. Moreover, $\Phi_{N j}^{N}(j \neq N)$ is equal to -1 . In addition, the parameters of the end-members in all sub-binary systems shown in Equation (4) are from Refs. [23-30], as listed in Table 2. These parameters are fixed during the evaluation. Different sets of interaction parameters were then adjusted to best fit the experimental concentration/interdiffusion flux profiles measured from the 3 diffusion multiples. On the basis of the final optimal set of model parameters, the concentration-dependent interdiffusivities in fcc Al-Co-Cr-Fe-Ni alloys at different temperatures can be calculated using Equation (2).

Table 2. List of the assessed mobility parameters during evaluation of the composition-dependent interdiffusion coefficients in fcc $\mathrm{Al}-\mathrm{Co}-\mathrm{Cr}-\mathrm{Fe}-\mathrm{Ni}$ HEAs at different temperatures.

\begin{tabular}{|c|c|c|}
\hline Mobility & Parameters & References \\
\hline \multirow{7}{*}{ Mobility of $\mathrm{Al}$} & $\Delta G_{A l}^{A l}=-123111.6-97.34 \times T$ & [23] \\
\hline & $\Delta G_{A l}^{C l}=-275359-73.00 \times T$ & [23] \\
\hline & $\Delta G_{A l}^{C r}=-235000-82.00 \times T$ & [27] \\
\hline & $\Delta G_{A l}^{F e}=-242731.1-104.27 \times T$ & [23] \\
\hline & $\Delta G_{A l}^{N L}=-268381.0-71.04 \times T$ & [23] \\
\hline & ${ }^{0} \Delta G_{A l}^{A l, N i}=-308067.5+111.52 \times T$ & {$[23]$} \\
\hline & ${ }^{0} \Delta G_{A l}^{C o, C r}=-171201.69$ & This work \\
\hline
\end{tabular}


Table 2. Cont

\begin{tabular}{|c|c|c|}
\hline Mobility & Parameters & References \\
\hline \multirow{8}{*}{ Mobility of Co } & $\Delta G_{C \Omega}^{A l}=-172082-28.422 \times T$ & [23] \\
\hline & $\Delta G_{C o}^{C O}=-296542.9-74.48 \times T$ & [25] \\
\hline & $\Delta G_{C o}^{C r}=-235000-82 \times T$ & [28] \\
\hline & $\Delta G_{C o}^{F e}=-301900-76.58 \times T$ & [24] \\
\hline & $\Delta G_{C o}^{N i}=-284169-67.6 \times T$ & [26] \\
\hline & ${ }^{0} \Delta G_{C \Omega}^{C o, C r}=-130004.01$ & This work \\
\hline & ${ }^{0} \Delta G_{\mathrm{Co}}^{\mathrm{Co}, \mathrm{Fe}}=305495-201.71 \times \mathrm{T}$ & [26] \\
\hline & ${ }^{0} \Delta G_{\mathrm{Co}}^{\mathrm{Co}, \mathrm{Ni}}=10787-11.5 \times \mathrm{T}$ & {$[26]$} \\
\hline \multirow{6}{*}{ Mobility of $\mathrm{Cr}$} & $\Delta G_{C r}^{A l}=-261700-3.71 \times T$ & [27] \\
\hline & $\Delta G_{C r}^{C o}=-254464-91.30 \times T$ & [28] \\
\hline & $\Delta G_{C r}^{C r}=-235000-82.00 \times T$ & [29] \\
\hline & $\Delta G_{C r}^{F e}=-286000-71.9 \times T$ & [29] \\
\hline & $\Delta G_{C r}^{N i}=-287000-64.4 \times T$ & [29] \\
\hline & ${ }^{0} \Delta G_{C r}^{C o, C r}=-488782.02$ & This work \\
\hline \multirow{8}{*}{ Mobility of Fe } & $\Delta G_{F e}^{A l}=-214000-8.45 \times T$ & [30] \\
\hline & $\Delta G_{F e}^{C o}=-253301-97.97 \times T$ & [24] \\
\hline & $\Delta G_{F e}^{C P}=-235000-82.0 \times T$ & [29] \\
\hline & $\Delta G_{F e}^{F e}=-286000-79.54 \times T$ & [29] \\
\hline & $\Delta G_{F e}^{N i}=-287000-67.5 \times T$ & [29] \\
\hline & ${ }^{0} \Delta G_{F e}^{C o, C r}=-832923.77$ & This work \\
\hline & ${ }^{0} \Delta G_{F e}^{C o, F e}=-63300+48.68 \times T$ & [26] \\
\hline & ${ }^{0} \Delta G_{F e}^{F e, N i}=-115000+104 \times T$ & [29] \\
\hline \multirow{8}{*}{ Mobility of Ni } & $\Delta G_{N i}^{A l}=-268381.0-71.04 \times T$ & [23] \\
\hline & $\Delta G_{N i}^{C_{0}}=-270348-87.3 \times T$ & [26] \\
\hline & $\Delta G_{N i}^{C r}=-235000-82 \times T$ & [29] \\
\hline & $\Delta G_{N i}^{F e}=-286000-86 \times T$ & [29] \\
\hline & $\Delta G_{N i}^{N i}=-271377.6-81.79 \times T$ & [23] \\
\hline & ${ }^{N 1} \Delta G_{N i}^{C o, C r}=-69907.74$ & This work \\
\hline & ${ }^{0} \Delta G_{N i}^{C o, N i}=7866+7.65 \times T$ & [26] \\
\hline & ${ }^{0} \Delta G_{N i}^{F e, N i}=124000-51.4 \times T$ & [29] \\
\hline
\end{tabular}

The obtained diagonal interdiffusivities $\widetilde{D}_{A l A l}^{N i}, \widetilde{D}_{\mathrm{CoCo}}^{N i}, \widetilde{D}_{\mathrm{CrCr}}^{N i}$, and $\widetilde{D}_{\mathrm{FeFe}}^{\mathrm{Ni}}$ along the diffusion paths in the 3 diffusion multiples are presented in Figures 2-4, and all of the digital files are provided in the electronic Supplementary Materials. The obtained diagonal interdiffusion coefficients are in the same order of magnitude as those limited data obtained by Kulkarni and Chauhan [10] and Chen and Zhang [13]. As shown in the figures, all of the diagonal interdiffusivities for the 3 diffusion multiples are positive, which is expected. The diagonal interdiffusivities $\widetilde{D}_{A l A l}^{N i}$ and $\widetilde{D}_{C o C o}^{N i}$ vary significantly with alloy compositions, whereas the variations in $\widetilde{D}_{\mathrm{CrCr}}^{\mathrm{Ni}}$ and $\widetilde{D}_{\mathrm{FeFe}}^{\mathrm{Ni}}$ with alloy compositions are relatively weak. Within the investigated composition and temperature ranges, the diagonal interdiffusivity $\widetilde{D}_{A l A l}^{N i}$ is the largest, followed by $\widetilde{D}_{C o C o}^{N i}, \widetilde{D}_{C r C r}^{N i}$ and $\widetilde{D}_{F e F e}^{N i}$ indicating that the component sequence with the fastest diffusion rate (the highest interdiffusion coefficient) to the slowest is $\mathrm{Al}>\mathrm{Co}>\mathrm{Cr}>\mathrm{Fe}$ in the present fcc $\mathrm{Al}-\mathrm{Co}-\mathrm{Cr}-\mathrm{Fe}-\mathrm{Ni}$ high-entropy alloys. In addition, all diagonal interdiffusivities $\widetilde{D}_{A l A l}^{N i}, \widetilde{D}_{\mathrm{CoCo}}^{N i}, \widetilde{D}_{\mathrm{CrCr}}^{\mathrm{Ni}}$, and $\widetilde{D}_{\mathrm{FeFe}}^{\mathrm{Ni}}$ increase from $1273 \mathrm{~K}$ to $1373 \mathrm{~K}$. Fe is also considered as the dependent component for comparison among the diagonal interdiffusivity of $\mathrm{Ni}$ and those of the other components in the 3 diffusion multiples. The results presented in Figure 5 show that the diagonal interdiffusivity $\widetilde{D}_{\mathrm{NiNi}}^{F e}$ is close to $\widetilde{D}_{\mathrm{CoC} o}^{F e}$. 

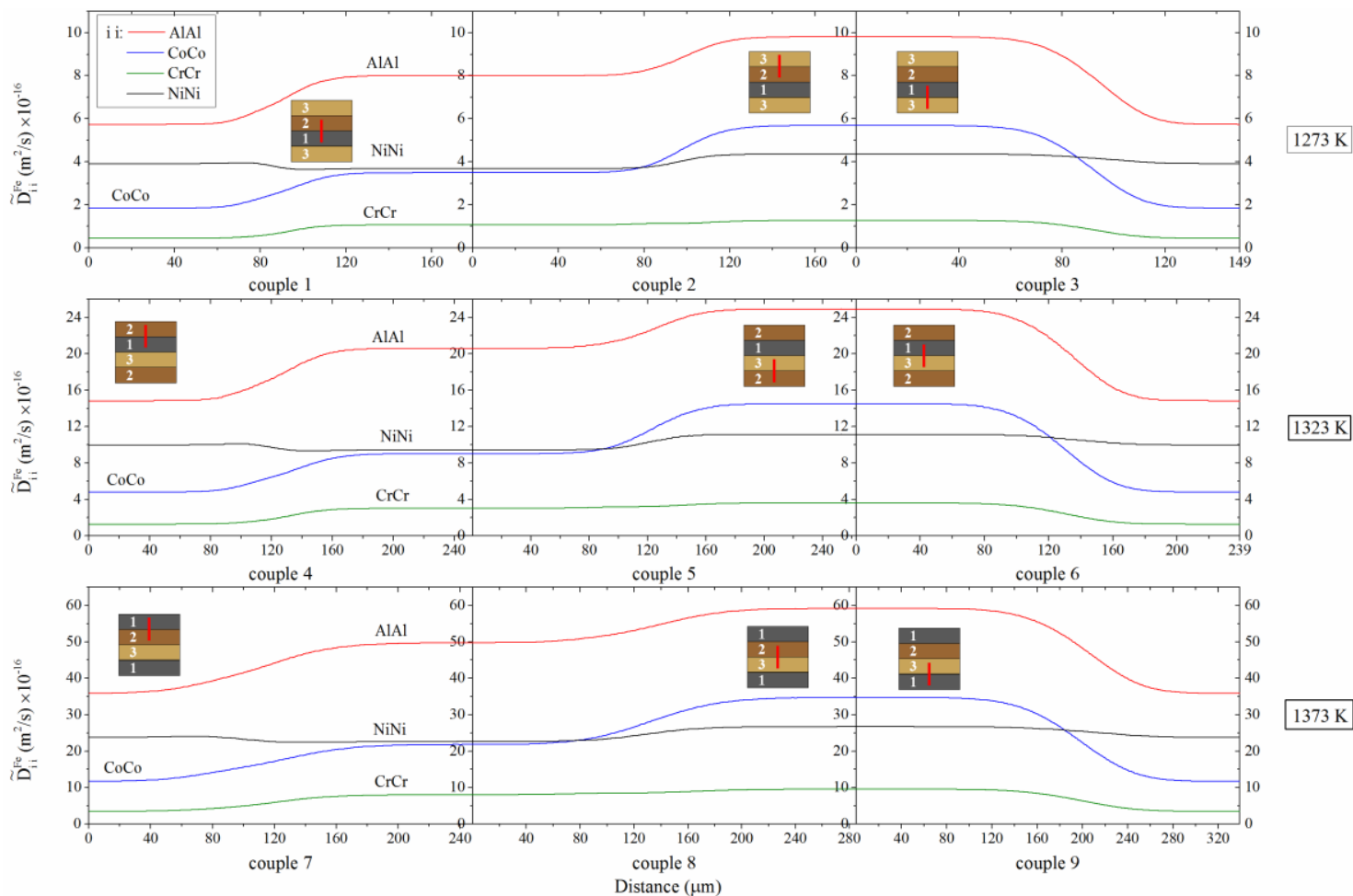

Figure 5. Comparison among the evaluated diagonal interdiffusivities for $\mathrm{Al}, \mathrm{Co}, \mathrm{Cr}$, and $\mathrm{Ni}$ in the diffusion multiples annealed for $46 \mathrm{~h}$ at $1273 \mathrm{~K}, 1323 \mathrm{~K}$ and $1373 \mathrm{~K}$, respectively, where Fe is taken as the dependent component.

The complete interdiffusivity matrices over the investigated composition and temperature ranges may be acquired using the numerical inverse method. The large quantities of off-diagonal interdiffusivities and the comparison among the interdiffusivities for each component in both situations-i.e., with $\mathrm{Ni}$ as the dependent component and Fe as the dependent component-are all presented in the electronic Supplementary Materials. As shown in the figures, when Ni is considered as the dependent component, the off-diagonal interdiffusivity $\widetilde{D}_{i F e}^{N i}(i \neq F e)$ is the largest, followed by $\widetilde{D}_{i \mathrm{Cr}}^{N i}(i \neq C r), \widetilde{D}_{i \mathrm{Co}}^{N i}(i \neq C o)$, and $\widetilde{D}_{i A l}^{N i}(i \neq A l)$; that is, $\widetilde{D}_{i F e}^{N i}(i \neq F e)>\widetilde{D}_{i \mathrm{Cr}}^{N i}(i \neq$ $C r)>\widetilde{D}_{i \text { Co }}^{N i}(i \neq C o)>\widetilde{D}_{i A l}^{N i}(i \neq A l)$. Meanwhile, when Fe is considered as the dependent component, the off-diagonal interdiffusivity $\widetilde{D}_{i N i}^{F e}(i \neq N i)$ is close to $\widetilde{D}_{i}^{F e} C_{0}(i \neq C o)$, and the sequence is $\widetilde{D}_{i \mathrm{Cr}}^{F e}(i \neq \mathrm{Cr})>\widetilde{D}_{i \mathrm{Co}}^{F e}(i \neq \mathrm{Co}) / \widetilde{D}_{i \mathrm{Ni}}^{F e}(i \neq N i)>\widetilde{D}_{i}^{F e} A l(i \neq A l)$.

Given that a single fcc phase was merely observed in the investigated alloy compositions for the present $\mathrm{Al}-\mathrm{Co}-\mathrm{Cr}-\mathrm{Fe}-\mathrm{Ni}$ alloys, the effect of excess contribution on the Gibbs energy might be negligible. Thus, the ideal solution model can sufficiently describe the present fcc $\mathrm{Al}-\mathrm{Co}-\mathrm{Cr}-\mathrm{Fe}-\mathrm{Ni}$ quinary system. This argument is also verified on the basis of the thermodynamic calculations by using the database TCHEA2 (Thermo-Calc 2017b) released by Thermo-Calc Software AB [31]. In this case, the obtained atomic mobilities shown in Equation (4) during the evaluation of the interdiffusivities can be considered reliable. Thus, by means of the Einstein relation $D_{i}^{*}=R T M_{i}$, the tracer diffusivity $D_{i}^{*}$ for different components can be in direct relation to the atomic mobility $M_{i}$. The evaluated temperature-dependent tracer diffusivities $D_{\mathrm{Al}}^{*}, D_{\mathrm{C} 0^{\prime}}^{*} D_{\mathrm{Cr}}^{*}, D_{\mathrm{Fe}}^{*}$, and $D_{\mathrm{Ni}}^{*}$, which are attributed to the assessed atomic mobilities in the present 3 alloys, are presented in Figure 6. 
To assess whether diffusion is sluggish in the present HEAs, the diagonal interdiffusivities (Ni is regarded as the dependent component) $\widetilde{D}_{A l A l}^{N i}, \widetilde{D}_{C o C o}^{N i}, \widetilde{D}_{C r C r}^{N i}$, and $\widetilde{D}_{F e F e}^{N i}$ in the current 3 $\mathrm{Al}-\mathrm{Co}-\mathrm{Cr}-\mathrm{Fe}-\mathrm{Ni}$ alloys are first compared with those in the other lower-order fcc alloys [32-36] with similar elements available in the literature. As presented in Figure 7, for $\mathrm{Al}, \mathrm{Cr}$, and $\mathrm{Fe}$, all diagonal interdiffusivities in the present 3 HEAs at 1273, 1323, and $1373 \mathrm{~K}$ are lower than those in the lower-order alloys (i.e., $\mathrm{Al}_{6} \mathrm{Ni}_{94}$ [32], $\mathrm{Al}_{3.76} \mathrm{Co}_{14.7} \mathrm{Ni}_{81.54}$ [33], $\mathrm{Al}_{7.7} \mathrm{Cr}_{9.7} \mathrm{Ni}_{82.6}$ [34], $\mathrm{Fe}_{40} \mathrm{Ni}_{60}$ [35], and $\mathrm{Co}-\mathrm{Cr}-\mathrm{Fe}-\mathrm{Ni}$ [10] alloys). Meanwhile, sluggish diffusion for Co exists only at $1273 \mathrm{~K}$-i.e., the sluggish diffusion effect can be observed only for $\mathrm{Al}, \mathrm{Cr}$, and $\mathrm{Fe}$ in the present HEAs. Subsequently, for further analysis, the tracer diffusivities of the 5 elements in the present fcc $\mathrm{Al}-\mathrm{Co}-\mathrm{Cr}-\mathrm{Fe}-\mathrm{Ni}$ alloys as well as in different fcc elements and conventional alloys with similar elements available in the literature are plotted against the inverse homologous temperature $T_{\mathrm{m}} / T$ and the inverse temperature $T^{-1}$, as demonstrated in Figure 6. As shown in Figure 6a, the tracer diffusivities of $\mathrm{Al}, \mathrm{Co}, \mathrm{Cr}$, and $\mathrm{Fe}$ in the present quaternary HEA $\mathrm{Co}_{25.33} \mathrm{Cr}_{25.77} \mathrm{Fe}_{24.53} \mathrm{Ni}_{24.37}$ are lower than those in the present quinary HEAs $\mathrm{Al}_{4.88} \mathrm{Co}_{29.53} \mathrm{Cr}_{18.58} \mathrm{Fe}_{19.62} \mathrm{Ni}_{27.39}$ and $\mathrm{Al}_{6.64} \mathrm{Co}_{23.82} \mathrm{Cr}_{23.66} \mathrm{Fe}_{23.01} \mathrm{Ni}_{22.87}$. The temperature-dependent tracer diffusivities of $\mathrm{Al}$ in the present $3 \mathrm{HEAs}$ are higher than the tracer diffusivity of $\mathrm{Al}$ in $\mathrm{Ni}$ [37]. $\mathrm{Co}$ in the present HEA $\mathrm{Al}_{6.64} \mathrm{Co}_{23.82} \mathrm{Cr}_{23.66} \mathrm{Fe}_{23.01} \mathrm{Ni}_{22.87}$ has the highest tracer diffusivities, whereas pure Co [38] has the lowest tracer diffusivities. Moreover, all tracer diffusivities of $\mathrm{Ni}$ in the present 3 HEAs are higher than those of $\mathrm{Ni}$ in the other fcc pure elements and alloys (i.e., pure $\mathrm{Ni}$ [39], $\mathrm{Fe}-15 \mathrm{Cr}-20 \mathrm{Ni}$ [40], $\mathrm{Co}_{25} \mathrm{Cr}_{25} \mathrm{Fe}_{25} \mathrm{Ni}_{25}$ [12], $\mathrm{Co}_{20} \mathrm{Cr}_{20} \mathrm{Fe}_{20} \mathrm{Mn}_{20} \mathrm{Ni}_{20}$ [12], $\mathrm{Co}_{22.22} \mathrm{Cr}_{22.22} \mathrm{Fe}_{22.22} \mathrm{Mn}_{11.12} \mathrm{Ni}_{22.22}$ [11], and $\mathrm{Al}_{20} \mathrm{Co}_{20} \mathrm{Cr}_{20} \mathrm{Fe}_{20} \mathrm{Ni}_{20}$ [11] alloys). Therefore, no significant sluggish diffusion is observed for $\mathrm{Al}, \mathrm{Co}$, and $\mathrm{Ni}$ in the present $\mathrm{Al}-\mathrm{Co}-\mathrm{Cr}-\mathrm{Fe}-\mathrm{Ni} H E A s$. Meanwhile, the tracer diffusivities of elements $\mathrm{Cr}$ and $\mathrm{Fe}$ in the present $\mathrm{Al}-\mathrm{Co}-\mathrm{Cr}-\mathrm{Fe}-\mathrm{Ni}$ HEAs are lower than those in the other pure elements/alloys (i.e., pure Fe [41], pure $\mathrm{Ni} \mathrm{[42,43],} \mathrm{Fe}-15 \mathrm{Cr}-20 \mathrm{Ni}$ [40], $\mathrm{Co}_{22.22} \mathrm{Cr}_{22.22} \mathrm{Fe}_{22.22} \mathrm{Mn}_{11.12} \mathrm{Ni}_{22.22}$ [11], and $\mathrm{Al}_{20} \mathrm{Co}_{20} \mathrm{Cr}_{20} \mathrm{Fe}_{20} \mathrm{Ni}_{20}$ [11] alloys). With reference to Figure $6 \mathrm{a}$, when the inverse absolute temperature $\mathrm{T}^{-1}$ is used for comparison, sluggish diffusion can be observed only for $\mathrm{Fe}$ and $\mathrm{Cr}$ in the present HEAs. When the comparison is made against the inverse homologous temperature $T_{\mathrm{m}} / T$, as shown in Figure $6 \mathrm{~b}$, the 2 curves of the tracer diffusivities of $\mathrm{Al}$ in the present $\mathrm{Co}_{25.33} \mathrm{Cr}_{25.77} \mathrm{Fe}_{24.53} \mathrm{Ni}_{24.37}$ and $\mathrm{Al}_{6.64} \mathrm{Co}_{23.82} \mathrm{Cr}_{23.66} \mathrm{Fe}_{23.01} \mathrm{Ni}_{22.87}$ alloys coincide; the 2 curves of the tracer diffusivities of $\mathrm{Co}$ in the present $\mathrm{Al}_{4.88} \mathrm{Co}_{29.53} \mathrm{Cr}_{18.58} \mathrm{Fe}_{19.62} \mathrm{Ni}_{27.39}$ and $\mathrm{Al}_{6.64} \mathrm{Co}_{23.82} \mathrm{Cr}_{23.66} \mathrm{Fe}_{23.01} \mathrm{Ni}_{22.87}$ alloys also coincide. Obviously, when comparison is made against the inverse homologous temperature $T_{\mathrm{m}} / T$, the result is the same as that when the comparison is made against the inverse absolute temperature $T^{-1}$, that is, the diffusion is sluggish only for Fe and $\mathrm{Cr}$ in the present HEAs. 


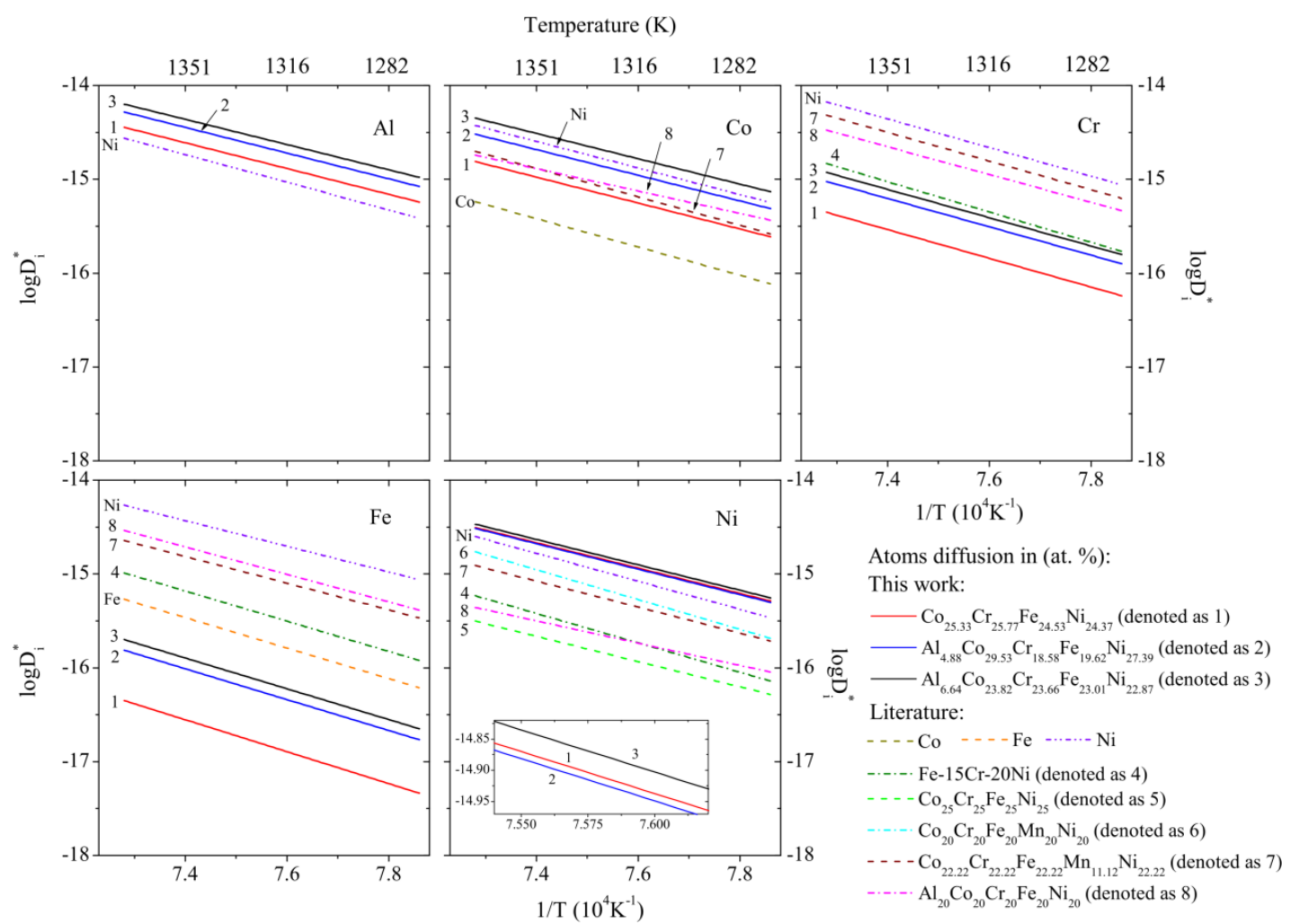

(a)
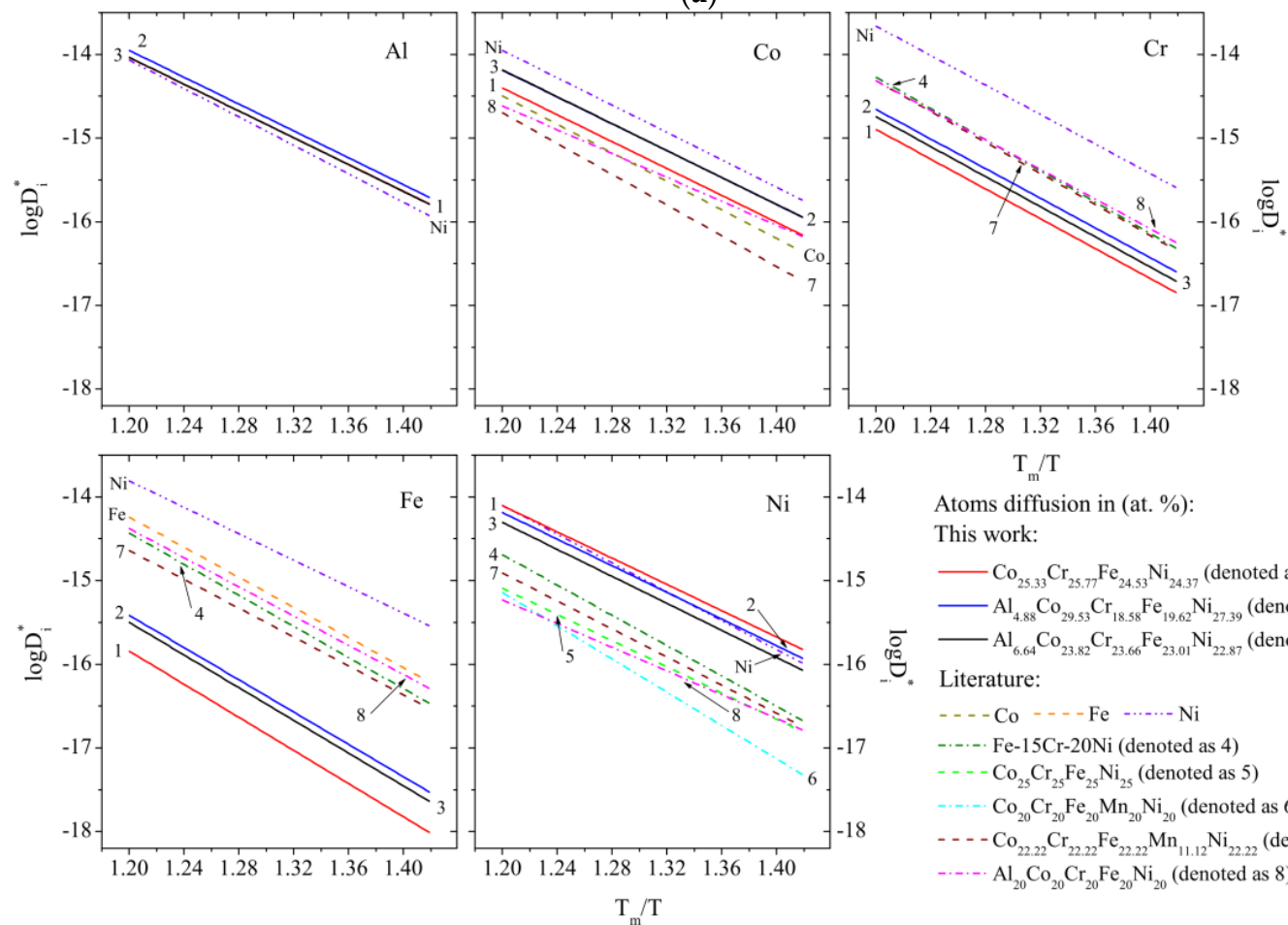

Atoms diffusion in (at. \%):

This work:

- $\mathrm{Co}_{25.33} \mathrm{Cr}_{25.77} \mathrm{Fe}_{24.53} \mathrm{Ni}_{24.37}$ (denoted as 1)

$-\mathrm{Al}_{4.88} \mathrm{Co}_{29.53} \mathrm{Cr}_{18.58} \mathrm{Fe}_{19.62} \mathrm{Ni}_{27.39}$ (denoted as 2)

$\underset{\square}{-}-\mathrm{Al}_{6,64} \mathrm{Co}_{23.82} \mathrm{Cr}_{23.66} \mathrm{Fe}_{23.01} \mathrm{Ni}_{22.87}$ (denoted as 3)

Literature:

- - - - Co - - - Fe - - - - - Ni

-...- $\mathrm{Fe}-15 \mathrm{Cr}-20 \mathrm{Ni}$ (denoted as 4)

- - $\mathrm{Co}_{25} \mathrm{Cr}_{25} \mathrm{Fe}_{25} \mathrm{Ni}_{25}$ (denoted as 5)

-... $\mathrm{Co}_{20} \mathrm{Cr}_{20} \mathrm{Fe}_{20} \mathrm{Mn}_{20} \mathrm{Ni}_{20}$ (denoted as 6)

- - - $\mathrm{Co}_{22.22} \mathrm{Cr}_{22.22} \mathrm{Fe}_{22.22} \mathrm{Mn}_{11.12} \mathrm{Ni}_{22.22}$ (denoted as 7)

-... $\mathrm{Al}_{20} \mathrm{Co}_{20} \mathrm{Cr}_{20} \mathrm{Fe}_{20} \mathrm{Ni}_{20}$ (denoted as 8)

(b)

Figure 6. Tracer diffusivities estimated in present work and comparison with the literature data on diffusion in various fcc pure metals and alloys: pure Co [38], pure Fe [41], Al in Ni [37], $\mathrm{Co}$ in $\mathrm{Ni}$ [44], $\mathrm{Cr}$ in $\mathrm{Ni}$ [42], Fe in $\mathrm{Ni}$ [43], pure $\mathrm{Ni}$ [39], $\mathrm{Fe}-15 \mathrm{Cr}-20 \mathrm{Ni}$ [40], $\mathrm{Co}_{25} \mathrm{Cr}_{25} \mathrm{Fe}_{25} \mathrm{Ni}_{25}$ [12], $\mathrm{Co}_{20} \mathrm{Cr}_{20} \mathrm{Fe}_{20} \mathrm{Mn}_{20} \mathrm{Ni}_{20}$ [12], $\mathrm{Co}_{22.22} \mathrm{Cr}_{22.22} \mathrm{Fe}_{22.22} \mathrm{Mn}_{11.12} \mathrm{Ni}_{22.22}$ [11], $\mathrm{Al}_{20} \mathrm{Co}_{20} \mathrm{Cr}_{20} \mathrm{Fe}_{20} \mathrm{Ni}_{20}$ [11] plotted as a function of (a) the inverse absolute temperature and (b) the inverse homologous temperature. 

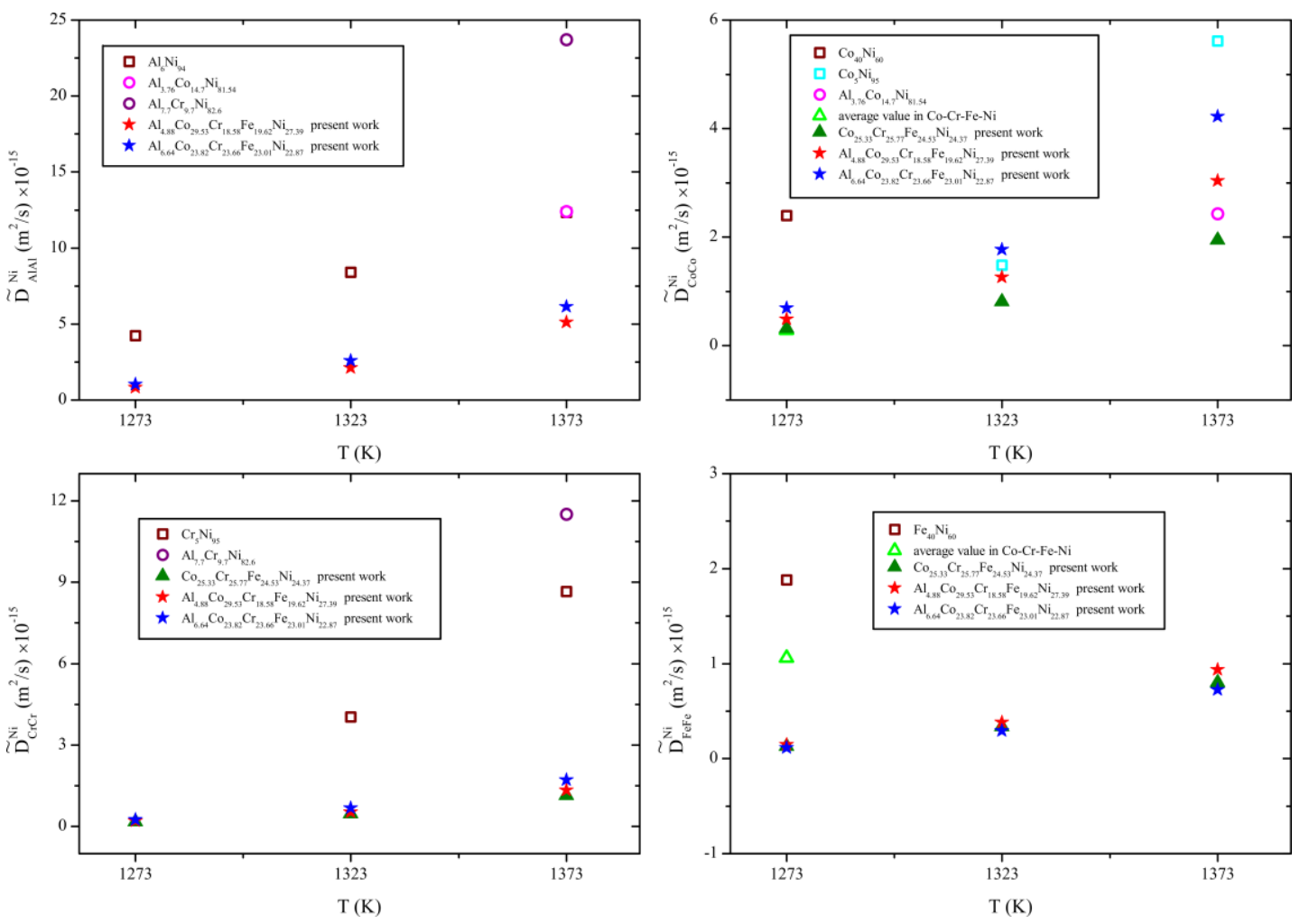

Figure 7. Comparison among the evaluated diagonal interdiffusivities for $\mathrm{Al}, \mathrm{Co}, \mathrm{Cr}$ and $\mathrm{Fe}$ in present work when $\mathrm{Ni}$ is taken as the dependent component and the literature data in the other fcc alloys: $\mathrm{Al}_{6} \mathrm{Ni}_{94}$ [32], $\mathrm{Al}_{3.76} \mathrm{Co}_{14.7} \mathrm{Ni}_{81.54}$ [33], $\mathrm{Al}_{7.7} \mathrm{Cr}_{9.7} \mathrm{Ni}_{82.6}$ [34], $\mathrm{Co}_{40} \mathrm{Ni}_{60}$ [35], $\mathrm{Fe}_{40} \mathrm{Ni}_{60}$ [35], $\mathrm{Co}_{5} \mathrm{Ni}_{95}$ [36], $\mathrm{Co}-\mathrm{Cr}-\mathrm{Fe}-\mathrm{Ni}[10]$.

\section{Conclusions}

In summary, the composition-dependent interdiffusion coefficients in fcc $\mathrm{Al}-\mathrm{Co}-\mathrm{Cr}-\mathrm{Fe}-\mathrm{Ni}$ HEAs at $1273 \mathrm{~K}, 1323 \mathrm{~K}$, and $1373 \mathrm{~K}$ were evaluated by using the recently developed numerical inverse method combined with concentration profiles from diffusion couples and multiples. The reliability of the obtained interdiffusion coefficients were verified by comparing the simulated composition/interdiffusion flux profiles with the corresponding experimental ones. The tracer diffusivities of the components were also evaluated based on the interdiffusivities and the simplified thermodynamic description. The comprehensive comparison between the diagonal interdiffusivities ( $\mathrm{Ni}$ is regarded as the dependent component) in the present HEAs and those in fcc conventional alloys shows that sluggish diffusion can be observed only for $\mathrm{Al}, \mathrm{Cr}$, and $\mathrm{Fe}$ in the present HEAs. The results of the comparison of the tracer diffusivities indicate that the significant sluggish diffusion is only observed for $\mathrm{Cr}$ and $\mathrm{Fe}$ in the present HEAs. Therefore, the sluggish diffusion effect is not true for all the elements in the present $\mathrm{Al}-\mathrm{Co}-\mathrm{Cr}-\mathrm{Fe}-\mathrm{Ni}$ alloys.

Supplementary Materials: The following are available online at www.mdpi.com/2075-4701/8/1/16/s1.

Acknowledgments: The financial support from the National Natural Science Foundation of China (Grant No. 51474239), and the National Key Research and Development Program of China (Grant No. 2016YFB0301101) is acknowledged. Lijun Zhang acknowledges financial support from the project supported by State Key Laboratory of Powder Metallurgy Foundation, Central South University, Changsha, China.

Author Contributions: Lijun Zhang, Weimin Chen and Qin Li conceived and designed the experiments; Qin Li performed the experiments; Qin Li, Jing Zhong and Lijun Zhang analyzed the data; Qin Li, Lijun Zhang, Qing Chen and Zi-Kui Liu wrote the paper.

Conflicts of Interest: The authors declare no conflict of interest. 


\section{References}

1. Huang, K.H.; Yeh, J.W. A Study on the Multicomponent Alloy Systems Containing Equal-mole Elements. Master's Thesis, National Tsing Hua University, Hsinchu, Taiwan, 1996.

2. Zhang, Y.; Zuo, T.T.; Tang, Z.; Gao, M.C.; Dahmen, K.A.; Liaw, P.K.; Lu, Z.P. Microstructures and properties of high-entropy alloys. Prog. Mater. Sci. 2014, 61, 1-93. [CrossRef]

3. Miracle, D.B.; Miller, J.D.; Senkov, O.N.; Woodward, C.; Uchic, M.D.; Tiley, J. Exploration and development of high entropy alloys for structural applications. Entropy 2014, 16, 494-525. [CrossRef]

4. Yeh, J.W.; Chen, S.K.; Lin, S.J.; Gan, J.Y.; Chin, T.S.; Shun, T.T.; Tsau, C.H.; Chang, S.Y. Nanostructured high-entropy alloys with multiple principal elements: Novel alloy design concepts and outcomes. Adv. Eng. Mater. 2004, 6, 299-303. [CrossRef]

5. Yeh, J.W. Recent progress in high-entropy alloys. Ann. Chim. 2006, 31, 633-648. [CrossRef]

6. Murty, B.S.; Yeh, J.W.; Ranganathan, S. High-Entropy Alloys; Butterworth-Heinemann: Boston, MA, USA, 2014; pp. 1-204.

7. Gao, M.C.; Zhao, J.C.; Morral, J.E. The Thermodynamics and Kinetics of High-Entropy Alloys. J. Phase Equilib. Diffus. 2017, 38, 351-352. [CrossRef]

8. Tsai, K.Y.; Tsai, M.H.; Yeh, J.W. Sluggish diffusion in Co-Cr-Fe-Mn-Ni high-entropy alloys. Acta Mater. 2013, 61, 4887-4897. [CrossRef]

9. Beke, D.L.; Erdélyi, G. On the diffusion in high-entropy alloys. Mater. Lett. 2016, 164, 111-113. [CrossRef]

10. Kulkarni, K.; Chauhan, G.P.S. Investigations of quaternary interdiffusion in a constituent system of high entropy alloys. AIP Adv. 2015, 5, 299-303. [CrossRef]

11. Dąbrowa, J.; Kucza, W.; Cieślak, G.; Kulik, T.; Danielewski, M.; Yeh, J.W. Interdiffusion in the FCC-structured Al-Co-Cr-Fe-Ni high entropy alloys: Experimental studies and numerical simulations. J. Alloys Compd. 2016, 674, 455-462. [CrossRef]

12. Vaidya, M.; Trubel, S.; Murty, B.S.; Wilde, G.; Divinski, S.V. Ni tracer diffusion in CoCrFeNi and CoCrFeMnNi high entropy alloys. J. Alloys Compd. 2016, 688, 994-1001. [CrossRef]

13. Chen, W.; Zhang, L. High-Throughput Determination of Interdiffusion Coefficients for Co-Cr-Fe-Mn-Ni High-Entropy Alloys. J. Phase Equilib. Diffus. 2017, 38, 457-465. [CrossRef]

14. Verma, V.; Tripathi, A.; Kulkarni, K.N. On Interdiffusion in FeNiCoCrMn High Entropy Alloy. J. Phase Equilib. Diffus. 2017, 38, 445-456. [CrossRef]

15. Chen, W.; Zhang, L.; Du, Y.; Tang, C.; Huang, B. A pragmatic method to determine the compositiondependent interdiffusivities in ternary systems by using a single diffusion couple. Scr. Mater. 2014, 90-91, 53-56. [CrossRef]

16. Chen, W.; Zhong, J.; Zhang, L. An augmented numerical inverse method for determining the composition-dependent interdiffusivities in alloy systems by using a single diffusion couple. MRS Commun. 2016, 6, 295-300. [CrossRef]

17. HITDIC. Available online: https://hitdic.com/ (accessed on 5 December 2017).

18. Xu, H.; Chen, W.; Zhang, L.; Du, Y.; Tang, C. High-throughput determination of the composition-dependent interdiffusivities in Cu-rich FCC Cu-Ag-Sn alloys at 1073 K. J. Alloys Compd. 2015, 644, 687-693. [CrossRef]

19. Chen, J.; Zhang, L.; Zhong, J.; Chen, W.; Du, Y. High-throughput measurement of the composition-dependent interdiffusivity matrices in Ni-rich fcc Ni-Al-Ta alloys at elevated temperatures. J. Alloys Compd. 2016, 688, 320-328. [CrossRef]

20. Wen, S.; Tang, Y.; Zhong, J.; Zhang, L.; Du, Y.; Zheng, F. High-throughput measurements of interdiffusivity matrices in face centered cubic Ni-Al-Mo alloys at 1273-1473 K. J. Mater. Res. 2017, 32, 2188-2201. [CrossRef]

21. Deng, S.; Chen, W.; Zhong, J.; Zhang, L.; Du, Y.; Chen, L. Diffusion study in bcc_A2 Fe-Mn-Si system: Experimental measurement and CALPHAD assessment. Calphad 2017, 56, 230-240. [CrossRef]

22. Zhang, C.; Zhang, F.; Chen, S.; Cao, W. Computational Thermodynamics Aided High-Entropy Alloy Design. JOM 2012, 64, 839-845. [CrossRef]

23. Zhang, L.; Du, Y.; Chen, Q.; Steinbach, I.; Huang, B. Atomic mobilities and diffusivities in the fcc, L12 and B2 phases of the Ni-Al system. Int. J. Mater. Res. 2010, 101, 1461-1475. [CrossRef]

24. Badia, M.; Vignes, A. Iron, nickel, and cobalt diffusion in iron-group transition metals. Acta Met. 1969, 17, 177-187. [CrossRef] 
25. Zhang, L.; Du, Y.; Ouyang, Y.; Xu, H.; Lu, X.G.; Liu, Y.; Kong, Y.; Wang, J. Atomic mobilities, diffusivities and simulation of diffusion growth in the Co-Si system. Acta Mater. 2008, 56, 3940-3950. [CrossRef]

26. Campbell, C.E.; Boettinger, W.J.; Kattner, U.R. Development of a diffusion mobility database for Ni-base superalloys. Acta Mater. 2002, 50, 775-792. [CrossRef]

27. Engström, A.; Ågren, J. Assessment of diffusional mobilities in face-centered cubic Ni-Cr-Al alloys. Z. Metallkd. 1996, 87, 92-97.

28. Zhang, W.; Liu, D.; Zhang, L.; Du, Y.; Huang, B. Experimental investigation and computational study of atomic mobility in fcc ternary Co-Cr-W alloys. Calphad 2014, 45, 118-126. [CrossRef]

29. Jönsson, B. Assessment of the mobilities of $\mathrm{Cr}, \mathrm{Fe}$, and $\mathrm{Ni}$ in fcc. Cr-Fe-Ni alloys. Z. Metallkd. 1995, 86, 686-692.

30. Du, Y.; Chang, Y.A.; Huang, B.; Gong, W.; Jin, Z.; Xu, H.; Yuan, Z.; Liu, Y.; He, Y.; Xie, F.Y. Diffusion coefficients of some solutes in fcc. and liquid Al: Critical evaluation and correlation. Mater. Sci. Eng. A 2003, 363, 140-151. [CrossRef]

31. Thermo-Calc Software AB, TCHEA2 Thermodynamic Database. Available online: www.thermocalc.com/ products-services/databases/thermodynamic/ (accessed on 10 September 2017).

32. Yamamoto, T.; Takashima, T.; Nishida, K. Interdiffusion in the $\zeta$-solid solution of a Ni-Al system. Trans. Jpn. Inst. Met. 1980, 21, 601-608. [CrossRef]

33. Yang, Y.L.; Shi, Z.; Luo, Y.S.; Lu, Y.; Yang, S.Y.; Han, J.J.; Li, W.B.; Wang, C.P.; Liu, X.J. Interdiffusion and Atomic Mobility Studies in Ni-Rich fcc Ni-Co-Al Alloys. J. Phase Equilib. Diffus. 2016, 37, 269-276. [CrossRef]

34. Dayananda, M.A.; Sohn, Y.H. A new analysis for the determination of ternary interdiffusion coefficients from a single diffusion couple. Metall. Mater. Trans. A 1999, 30, 535-543. [CrossRef]

35. Ustad, T.; Sorum, H. Interdiffusion in the iron-nickel, nickel-cobalt, and iron-cobalt systems. Phys. Status Solidi A 1973, 20, 285-294. [CrossRef]

36. Jung, S.B.; Yamane, T.; Minamino, Y.; Hirao, K.; Araki, H.; Saji, S. Interdiffusion and its size effect in nickel solid solutions of nickel-cobalt, nickel-chromium and nickel-titanium. J. Mater. Sci. Lett. 1992, 11, 1333-1337. [CrossRef]

37. Lee, C.G.; Youn, K.T.; Cho, H.H.; Lee, Y.I.; Yoo, D.S.; Shimozaki, T. Measurement of the impurity diffusion of $\mathrm{Al}$ in Ni by laser induced breakdown spectrometry (LIBS). Diffus. Defect Data Part A 2001, 194-199, 109-114. [CrossRef]

38. Bussmann, W.; Herzig, C.; Rempp, W.; Maier, K.; Mehrer, H. Isotope effect and self-diffusion in face-centered cubic cobalt. Phys. Status Solidi A 1979, 56, 87-97. [CrossRef]

39. Bakker, H. Curvature in the $\ln \mathrm{D}$ versus $1 / \mathrm{T}$ plot for self-diffusion in nickel at temperatures from $980-1400^{\circ} \mathrm{C}$. Phys. Status Solidi B 1968, 28, 569-576. [CrossRef]

40. Rothman, S.J.; Nowicki, L.J.; Murch, G.E. Self-diffusion in austenitic iron-chromium-nickel alloys. J. Phys. F 1980, 10, 383-398. [CrossRef]

41. Ivantsov, I.G.; Blinkin, A.M. Self-diffusion in strongly diluted binary solution. III. Effect of tin, antimony, lead, and bismuth impurities on the self-diffusion of iron in the $\gamma$-phase. Fiz. Met. Metalloved. 1966, 22, 876-883.

42. Ruzickova, J.; Million, B. Self-diffusion of the components in the fcc. phase of binary solid solutions of the iron-nickel-chromium system. Mater. Sci. Eng. 1981, 50, 59-64. [CrossRef]

43. Heuer, C.F. Diffusion of Iron and Cobalt in Nickel Single Crystals. Ph.D. Thesis, University of Missouri-Rolla, Rolla, MO, USA, 1969.

44. Hirano, K.; Agarwala, R.P.; Averbaeh, B.L.; Cohen, M. Diffusion in cobalt-nickel alloys. J. Appl. Phys. 1962, 33, 3049-3054. [CrossRef]

(C) 2017 by the authors. Licensee MDPI, Basel, Switzerland. This article is an open access article distributed under the terms and conditions of the Creative Commons Attribution (CC BY) license (http:/ / creativecommons.org/licenses/by/4.0/). 